\title{
STUDI TINGKAT KEANEKARAGAMAN HAYATI LAHAN BEKAS TERBAKAR DI TAMAN NASIONAL SEBANGAU \& KAWASAN HUTAN DENGAN TUJUAN KHUSUS (KHDTK) TUMBANG NUSA
}

\section{STUDY OF BIODIVERSITY LEVEL ON BURNT LAND AT SEBANGAU NATIONAL $P A R K \&$ FOREST AREA WITH SPESIFIC PURPOSE (KHDTK) TUMBANG NUSA}

\author{
Mariaty ${ }^{1)}$, Ise Afitah $^{1)}$ dan Purwanto Budi Santosa ${ }^{2)}$ \\ 1) Program Studi Kehutanan Universitas Muhammadiyah Palangkaraya \\ ${ }^{2)}$ Balai Penelitian dan pengembangan Lingkungan Hidup \& Kehutanan Banjarbaru \\ email : iyoetkapuas@gmail.com.
}

\begin{abstract}
ABSTRAK
Kebakaran hutan dan lahan tahun 2015 mengakibatkan kerusakan yang luar bisa terhadap hutan kawasan di Taman Nasional Sabangau dan KHDTK Tumbang Nusa, dimana hingga kini kondisinya belum juga bisa pulih seperti semula. Penelitian ini bertujuan untuk mengetahui dampak kebakaran hutan dan lahan terhadap keanekaragaman hayati vegetasi dan proses suksesi yang terjadi di TN. Sabangau dan KHDTK Tumbang Nusa dengan metodelogi survei lapangan dan membuat petak ukur (PU) di lahan bekas terbakar dan tidak terbakar sebagai pembanding. Pengamatan dan pengumpulan data dilaksanakan sesuai dengan strata vegetasi yakni tingkat Semai, Pancang, Tiang dan Pohon. Analisis data menggunakan metode kuantitatif dengan menghitung Dominasi jenis, Keanekaragaman jenis, Kekayaan jenis dan Kemerataan Jenis.

Hasil penelitian menunjukan bahwa di Lahan tidak terbakar yang di amati di TN. Sabangau terdapat 29 jenis vegetasi, sedangkan bekas terbakar hanya didapatkan tumbuhan tingkat permudaan yakni Semai dan Pancang dimana di TN. Sabangau ada 2 jenis vegetasi dan di KHDTK Tumbang Nusa ada 4 jenis vegetasi. Untuk dominasi jenis ditunjukan dengan nilai INP yang tinggi, semakin besar nilai INP maka komposisi hutan tersebut cukup baik dilihat dari kerapatan dan juga frekwensi kehadiran jenisnya. Di Sabangau nilai dominasi tertinggi adalah Tutup Kabali (Diospyros pseudomalabarica) pada tingkat pohon, Rambutan Hutan (Nephelium lappaceum) untuk tingkat tiang dan pancang, serta Bangkinang (Elaeocarpus glaber $\mathrm{Bl}$ ) untuk tingkat semai, sedang di KHDTK adalah Milas/ Tumeh (Combretacarpus rotundatus) untuk tingkat Semai dan Pancang dan Gerunggang (Cratoxylon arborescens) untuk tingkat Tiang dan Pohon yang mendominasi. Analisis Angka keragaman jenis, kekayaan jenis dan kemerataan jenis di dua lokasi penelitian tidak menunjukan nilai yang tinggi dimana dari hasil pengolahan data nilai range-nya rendah hingga sedang, tidak ada yang tinggi.

Pada lahan bekas terbakar sangat lambat proses suksesi yang terjadi, hal ini dikarenakan lahan bekas terbakar mengalami degradasi lahan yang sangat parah dimana terjadi pengikisan/ penurunan permukaan tanah sehingga lantai hutan tergenang juga karena tajuk terbuka dan tidak ada naungan sehingga semak yang mendominasi.
\end{abstract}

Kata kunci: kebakaran hutan, Keanekaragaman hayati, suksesi 


\begin{abstract}
The forest and land fires in 2015 caused severe damage to forest areas at Sebangau National Park and KHDTK Tumbang Nusa, where the condition has not to be able to recover as before. This research objective is knowing the effect of forest and land fires on vegetation and the succession process that is happened at TN. Sebangau and KHDTK Tumbang Nusa with methodology field survey and making plots (PU) on the burnt and un-burnt forest for the comparison. Data observation and collection were done appropriately with the vegetation strata, namely the level of seedlings, saplings, poles, and trees. The data analysis used quantitative with calculating the Species Dominance, Species Diversity, Species Richness, and Species Evenness.

The research result shows the un-burnt land was observed in TN. Sebangau there are 29 vegetation species, meanwhile the burnt land there are found only rejuvenation level plants, namely Seedlings and Saplings where there are two vegetation species at TN. Sabangau and 4 vegetation species at KHDTK. For species dominance is indicated by a high INP value, the greater value of INP means the forest composition is good enough in terms of density and frequency of species presence. In Sebangau, the highest value of dominance is Tutup Kabali (Diospyros pseudomalabarica) for the tree level, Rambutan Hutan (Nephelium lappaceum) for pole and sapling levels, and Bangkinang (Elaeocarpus glaber $\mathrm{Bl}$ ) for seedling level, while in KHDTK is Milas/Tumeh (Combretacarpus rotundatus) for the seedling and sapling levels, and Gerunggang (Cratoxylon arborescens) for pole and tree levels. The Analysis Number of species diversity, richness, and evenness species in the two research locations do not show a high value which from data processing result shows the range is low to moderate, nothing high.

On burnt land, the succession process happens very slowly because it experienced the severe degradation of land causing the erosion/ subsidence of soil surface so that the forest floor was flooded as the impact of the open canopy and no shade from the bush that dominated.
\end{abstract}

Keywords: forest fire, biodiversity, succession

\section{PENDAHULUAN}

\section{Latar Belakang}

Kebakaran hutan merupakan salah satu penyebab terjadinya degradasi lahan yang dapat mempengaruhi pertumbuhan vegetasi dan jenis vegetasi yang berada di areal bekas kebakaran. Beberapa wilayah di indonesia pernah mengalami kebakaran hutan termasuk di Kalimantan Tengah salah satunya di Taman Nasional Sebangau dan KHDTK Tumbang Nusa. Tidak hanya faktor alam yang berpengaruh misalnya udara yang sangat panas disaat musim kemarau namun juga karena ulah manusia yang tidak sadar akan pentingnya hutan.

Hampir setiap tahun Kalimantan Tengah mengalami kebakaran hutan dan lahan pada tahun 2011 Kalimantan Tengah mengalami kebakaran seluas 22,00 Ha dan pada tahun 2015 menyebabkan kebakaran hutan dan lahan seluas 122.882,90 Ha. Kebakaran hutan dan lahan pada tahun 2015 sangat tinggi, hampir seluruh Kota 
dan Kabupaten seluruh Kalimantan Tengah mengalami kebakaran.

Sering terjadinya kebakaran hutan di Kalimantan Tengah yang salah satunya terjadi di Taman Nasional Sebangau dan KHDTK Taman Nasional, membuat keanekaraman vegetasi semakin berkurang. Masih banyak tumbuhan yang belum terdata setelah terjadi kebakaran di Kawasan tersebut. Kebakaran hutan dan lahan yang paling parah di Taman Nasional Sebangau dan KHDTK Tumbang Nusa terjadi pada bulan Oktober November tahun 2015.

\section{Tujuan Penelitian}

Untuk mengetahui dampak dari kebakaran hutan dan lahan tahun 2015 lalu terhadap tingkat keanekaragaman hayati mempengaruhi tingkat keanekaragaman jenis endemik rawa gambut di Taman Nasional Sebangau dan KHDTK Tumbang Nusa.

Penelitian ini juga mencoba mengidentifikasi proses suksesi yang terjadi dan faktor yang mempengaruhi pertumbuhan vegetasi pada area bekas terbakar dan tidak terbakar sebagai pembanding

\section{METODOLOGI}

Penelitiaan dilakukan di dua lokasi

yang berbeda berdasarkan sejarah kebakaran hutan, yaitu di lokasi hutan bekas terbakar Taman Nasional Sebangau dan hutan bekas terbakar di KHDTK Tumbang Nusa Pulang Pisau yang terbakar pada tahun 2015. Di dua lokasi tersebut, masing-masing dibuat tiga petak ukur (PU) untuk area bekas terbakar dan area yang tidak terbakar (sebagai pembanding). Plot yang di buat berdasarkan struktur pertumbuhannya yakni untuk tingkat Semai, Pancang, Tiang dan Pohon.

Data hasil pengamatan selanjutnya dihitung:

1. Nilai Kerapatan Relatif (KR), Frekuensi Relatif (FR) dan Dominansi Relatif (DR) serta Indeks Nilai Penting (INP).

2. Kemudian berdasarkan hasil Indeks Nilai Penting (INP) maka dapat dihitung Indeks Keanekaragaman jenis dengan menggunakan Indeks Keanekaragaman Shannon (Shannon index)

$$
\mathrm{H}^{\prime}=-\sum\left[\left(\frac{n i}{N}\right) \ln \left(\frac{n i}{N}\right)\right]
$$

3. Untuk menentukan kekayaan jenis dalam unit-unit pengamatan digunakan adalah indeks diversitas Margalef (Indriyanto 2006). Indeks margalef dihitung dengan menunjukan persamaan sebagai berikut:

$d=\frac{s-1}{\ln N}$

4. Kemerataan menunjukan tingkat penyebaran jenis pada suatu area 
hutan. Kisaran nilai Evenness antara 0-

1. Jika nilai Evenness semakin mendekati 1 berati semakin tinggi nilai kemerataannya yang mengindikasi komposisi penyebaran jenis semakin merata atau tidak didominasi oleh satu jenis tertentu (Indriyanto 2006). Nilai Evenness dapat dihitung menggunakan persamaan sebegai berikut:

$$
\mathrm{E}=\frac{H^{\prime}}{\ln S}
$$

\section{HASIL DAN PEMBAHASAN}

\section{Identifikasi Jenis}

Berdasarkan hasil pengamatan yang dilaksanakan pada area hutan yang bekas terbakar dan tidak terbakar di Sabangau dan KHDTK tumbang nusa didapatkan hasil sebagai berikut:

\begin{tabular}{|c|c|c|}
\hline \multicolumn{3}{|c|}{ Lahan Tidak Terbakar } \\
\hline \multicolumn{2}{|r|}{ Sabangau } & KHDTK Tumbang Nusa \\
\hline 1 & $\begin{array}{l}\text { Terentang (Campnosperma auriculata } \\
\text { Hook) }\end{array}$ & Sasendok (Ficus Deltoidea SP) \\
\hline 2 & Rambutan Hutan (Nephelium lappaceum) & Milas (Litsea Oppositifolia) \\
\hline 3 & Jambu-Jambuan (Eugenia sp) & Pasir-pasir (Stemonurus Scorpiodes) \\
\hline 4 & Tutup Kabali (Diospyros pseudomalabarica) & Nyatoh (Palaquium cochlearia) \\
\hline 5 & Bintangur (Calophyllum inophyllum) & Terentang (Campnosperma auriculata) \\
\hline 6 & Rengas Putih (Gluta rengas) & Jambu-jambu (Syzium spp.) \\
\hline 7 & Bangkinang (Elaeocarpus glaber BI.) & Madang Lengkuas (Macanga populifolia) \\
\hline 8 & Kambasira (Ilex cymosa) & Meranti Batu (Shorea parvifolia) \\
\hline 9 & Nyatoh (Palaquium sp) & Meranti Bunga (Shorea teysmanniana) \\
\hline 10 & Kaja (Dillenia excelsa) & Pintek (Litsea Oppositifolia) \\
\hline 11 & $\begin{array}{l}\text { Gantalam/ Manggis Hutan (Garcinia } \\
\text { parvifolia) }\end{array}$ & Pampaning (Quercur susericea) \\
\hline 12 & Kayu Gula (Litsea grandis) & Galam Tikus (Eugenia sp) \\
\hline 13 & Kamba Sira (Ilex cymosa) & Merapat (Combretocarpus rotundatus) \\
\hline 14 & Resak (Cotylelobiummelanoxylum) & Malam-malam/ Kalampuri (Diospyros malam) \\
\hline 15 & Ehang (Diospyros siamang Bakh.) & Rahanjang (Xylopia sp) \\
\hline 16 & Meranti Padi (Shorea parvifolia Dyer) & Nyatoh (Palaquium cochlearia) \\
\hline 17 & Kayu Kulat (Cantleya corniculata) & Gerunggang (Cratoxylon arborescens) \\
\hline 18 & Kayu Martibu (Dactylocladus stenotachys) & Manggis Hutan (Garcinia cf. Bancana) \\
\hline 19 & Mendarahan (Ardisia sp.) & Darah-darah (Horsfieldia sp) \\
\hline 20 & Meranti Batu (Shorea leprosula) & Martibu (Eugenia sp) \\
\hline 21 & Kaja Laki (Aglaia rubigunosa) & \\
\hline 22 & Kayu Bintan (Erycibe sp.) & \\
\hline 23 & Balangeran (Shorea balangeran) & \\
\hline 24 & Ramin (Gonystylus bancanus) & \\
\hline 25 & Parut (Callophylum sp) & \\
\hline
\end{tabular}




\begin{tabular}{|l|l|l|}
\hline 26 & Kayu Kacang (Cantleya corniculata) & \\
\hline 27 & Beringin (Ficus benjamina L) & \\
\hline 28 & Gambir (Uncaria sp) & \\
\hline 29 & Karurang/ Mahang (Macaranga triloba) & \\
\hline
\end{tabular}

Sumber: Data Lapangan (Data Primer)

Dari tabel di atas bisa dilihat bahwa pada lahan tidak terbakar ada sekitar 29 jenis vegetasi yang terdapat di Kawasan Hutan Taman Nasional Sabangau hasil identifikasi yang di peroleh pada 3 petak ukur contoh sedangkan di KHDTK Tumbang Nusa hanya terdapat sekitar 20 jenis vegetasi. Hal ini menunjukan bahwa di Hutan Sabangau jenis vegetasi lebih beragam ketimbang di KHDTK Tumbang Nusa. Beberapa jenis tanaman yakni:

diketemukan sama, tapi lebih banyak yang

berbeda. Berikut adalah 4 jenis tanaman yang sama yang di temukan baik di Sabangau maupun di KHDTK Tumbang Nusa yakni: Jambu-jambuan, Nyatoh, Manggis Hutan dan Terentang. Ke 4 jenis tanaman ini merupakan tanaman endemik di hutan rawa gambut.

Untuk kawasan pengamatan yang tidak terbakar diidentifikasi ada beberapa jenis vegetasi yang sudah mulai tumbuh

\begin{tabular}{|r|l|l|}
\hline \multicolumn{2}{|c|}{ Lahan Bekas } & Terbakar \\
\hline \multicolumn{2}{|c|}{ Sabangau } & \multicolumn{1}{c|}{ KHDTK Tumbang Nusa } \\
\hline 1 & Tempohot/ Tatumbu (Syzygium sp.) & Merapat/ Tumeh (Combretacarpus rotundatus) \\
\hline 2 & Kayu Kacang/kulat (Cantleya corniculata) & Gerunggang (Cratoxylon arborescens) \\
\hline 3 & & Blangeran (Shorea balangiran) \\
\hline 4 & & Jambu-jambuan (Syzigium spp.) \\
\hline
\end{tabular}

Data Primer: di KHDTK Tumbang Nusa dan TN. Sabangau

Pada lahan bekas terbakar tahun 2015 lalu kawasan lokasi pengamatan belum mengalami perkembangan perbaikan kondisi alami, terutama di TN. Sabangau dimana dari 3 petak ukur yang di buat hanya ada 2 jenis vegetasi yang mampu tumbuh, sedangkan di KHDTK Tumbang Nusa ada 4 jenis yang teridentifikasi. Di lokasi bekas terbakar justru semak belukar yang dominan tumbuh karena area yang terbuka dan sinar matahari cenderung langsung memapar lantai hutan tanpa ada tajuk yang memberikan naungan dan kondisi ini amat disukai untuk perkembangan semak belukar. Selain itu, karena adanya 
pengikisan lapisan permukaan tanah akibat dari kebakaran, lantai hutan cenderung basah, terlebih di Sabangau yang lokasinya dekat dengan sungai.

\section{Dominasi Jenis}

Komposisi jenis jenis di atas menunjukan banyaknya variasi jenis di masing-masing lokasi pengamatan, walau pun luas petak pengamatan masih hanya berkisar 0,12 ha namun demikian data yang di hasilkan paling tidak dapat menggambarkan bagaiamana komposisi penyusun vegetasi di masing-masing kawasan baik lahan tidak terbakar dan lahan bekas terbakar demikian juga dengan dominasi yang ditunjukan dengan besaran INP atau Indeks Nilai Penting.

Berikut adalah data 3 jenis yang mendominasi pada lahan tidak terbakar:

\begin{tabular}{|c|c|c|c|c|c|}
\hline No. & Jenis & KR (\%) & FR (\%) & DR (\%) & INP (\%) \\
\hline \multicolumn{6}{|c|}{ KHDTK Tumbang Nusa } \\
\hline & Semai (6 Jenis) & & & & \\
\hline 1. & Milas (Parasetamon Urophyllum) & 46,15 & 46,15 & - & 92,30 \\
\hline 2. & Pasir-pasir (Stemonurus Scorpiodes) & 26,92 & 26,92 & - & 53,84 \\
\hline 3. & Sasendok (Ficus Deltoidea SP) & 11,54 & 11,54 & - & 23,07 \\
\hline & Pancang (10 Jenis) & & & & \\
\hline 1. & Pintek (Litsea Oppositifolia) & 37,93 & 37,93 & - & 75,86 \\
\hline 2. & Milas (Parasetamon Urophyllum) & 10,34 & 10,34 & - & 20,68 \\
\hline 3. & Galam tikus (Eugenia sp) & 10.34 & 10 & - & 20,68 \\
\hline & Tiang (6 jenis) & & & & \\
\hline 1. & Gerunggang (Cratoxylon arborescens) & 35,71 & 35,71 & 61,66 & 133,09 \\
\hline 2. & Merapat (Combretocarpus rotundatus) & 28,57 & 28,57 & 29,21 & 86,35 \\
\hline 3. & Jambu-jambu (Syzium spp.) & 14,28 & 14,28 & 5,18 & 33,75 \\
\hline & Pohon (10 jenis) & & & & \\
\hline 1. & Gerunggang (Cratoxylon arborescens) & 80,10 & 15,00 & 80,10 & 175,20 \\
\hline 2. & Martibu (Eugenia sp) & 12,30 & 15,00 & 12,30 & 39,60 \\
\hline 3. & Meranti Batu (Shorea parvifolia) & 3,06 & & 3,06 & 21,13 \\
\hline \multicolumn{6}{|c|}{ TN. Sabangau } \\
\hline & Semai (7 Jenis) & & & & \\
\hline 1. & Bangkinang (Elaeocarpus glaber Bl.) & 48,71 & 11,11 & & 59,82 \\
\hline 2. & Terentang (Campnosperma auriculata Hook) & 12,82 & 11,11 & & 23,92 \\
\hline 3. & Rambutan hutan (Nephelium lappaceum) & 12,82 & 12,82 & & 35,04 \\
\hline \multirow{4}{*}{$\begin{array}{l}1 . \\
2 . \\
3 .\end{array}$} & Pancang (10 Jenis) & & & & \\
\hline & Rambutan hutan (Nephelium lappaceum) & 35,00 & 20,00 & & 55,00 \\
\hline & Jambu-jambu (Syzium spp.) & 15,00 & 13,33 & & 28,33 \\
\hline & Kambasira (llex cymosa) & 10,00 & & & 23,33 \\
\hline \multirow{4}{*}{$\begin{array}{l}1 . \\
2 .\end{array}$} & Tiang (6 jenis) & & & & \\
\hline & Rambutan hutan (Nephelium lappaceum) & 24,08 & 14,28 & 31,91 & 70,20 \\
\hline & Kambasira (Ilex cymosa) & 20,00 & 21,42 & 37,23 & 78,65 \\
\hline & Nyatoh (Palaquium sp) & 12,00 & 7,14 & 6,68 & 25,83 \\
\hline \multirow{4}{*}{$\begin{array}{l}1 . \\
2 . \\
3 .\end{array}$} & Pohon (17 Jenis) & & & & \\
\hline & Tutup Kabali (Diospyros pseudomalabarica) & 26,47 & 9,09 & 65,98 & 101,54 \\
\hline & Meranti (Shorea leprosula) & 11,76 & 9,09 & 7,71 & 28,56 \\
\hline & Rambutan hutan (Nephelium lappaceum) & 8,82 & 13,63 & 5,90 & 28,36 \\
\hline
\end{tabular}

Sumber: Pengolahan data Primer 
Pada Petak pengamatan di KHDTK untuk tingkat tiang dan Pohon ditemukan bahwa jenis yang paling banyak hadir adalah Gerunggang (Cratoxylon arborescens), dan justru pada tingkat permudaan semai dan pancang tanaman ini tidak ditemukan hal ini di karenakan jenis tersebut biasanya adalah tanaman pionir pada lahan yang mengalami degradasi dan permudaannya justru akan hadir pada kondisi penyinaran penuh (tajuk hutan terbuka). Di Sabangau, Rambutan Hutan (Nephelium lappaceum) justru hadir dan menjadi salah satu jenis dominan pada hampir seluruh strata vegetasi di lahan tidak terbakar dari tingkat permudaan hingga tingkat pohon hal ini menunjukan bahwa sebaran dan pertumbuhan jenis ini cukup baik dan bisa berdaptasi dengan baik di kondisi basah seperti TN. Sabangau.

Berikut adalah data dominasi jenis pada lahan bekas terbakar :

\begin{tabular}{|c|c|c|c|c|c|}
\hline No. & Jenis & KR (\%) & FR (\%) & DR (\%) & INP (\%) \\
\hline \multicolumn{6}{|c|}{ KHDTK Tumbang Nusa } \\
\hline 1. & $\begin{array}{l}\text { Semai (1 Jenis) } \\
\text { Gerunggang (Cratoxylon arborescens) }\end{array}$ & 1,00 & 1,00 & & 2,00 \\
\hline $\begin{array}{l}1 . \\
2 . \\
3 . \\
4 .\end{array}$ & $\begin{array}{l}\text { Pancang (4 jenis) } \\
\text { Tumeh (Combretacarpus rotundatus) } \\
\text { Gerunggang (Cratoxylon arborescens) } \\
\text { Balangeran (Shorea balangiran) } \\
\text { Jambu-jambu (Syzigium spp.) }\end{array}$ & $\begin{array}{l}33,33 \\
33,33 \\
16,66 \\
16,66\end{array}$ & $\begin{array}{l}33,33 \\
33,33 \\
16,66 \\
16,66\end{array}$ & & $\begin{array}{l}66,66 \\
66,66 \\
33,33 \\
33,33\end{array}$ \\
\hline 1. & $\begin{array}{l}\text { Tiang (1 jenis) } \\
\text { Tumeh/ Merapat (Combretacarpus rotundatus) }\end{array}$ & 100 & 100 & 100 & 300 \\
\hline & Pohon ( - ) & & & & \\
\hline \multicolumn{6}{|c|}{ TN. Sabangau } \\
\hline $\begin{array}{l}1 . \\
2\end{array}$ & $\begin{array}{l}\text { Semai (2 Jenis) } \\
\text { Tempohot/ Tatumbu (Syzygium sp.) } \\
\text { Kayu Kacang/kulat (Cantleya corniculata) }\end{array}$ & $\begin{array}{l}87,50 \\
12,50\end{array}$ & $\begin{array}{l}50,50 \\
50,50\end{array}$ & & $\begin{array}{r}137,50 \\
62,50\end{array}$ \\
\hline 1. & $\begin{array}{l}\text { Pancang (1 jenis) } \\
\text { Kayu Kacang/kulat (Cantleya corniculata) }\end{array}$ & 100,00 & 100,00 & & 200,00 \\
\hline 1. & Tiang ( - ) & & & & \\
\hline & Pohon ( - ) & & & & \\
\hline
\end{tabular}

Pada data vegetasi di lagan bekas terbakar, terutama di KHDTK Tumbang Nusa, Gerunggang (Cratoxylon arborescens) dan Tumeh (Combretacarpus rotundatus) mendominasi pertumbuhan untuk tingkat permudaan. Kedua jenis vegetasi ini memang merupakan jenis yang paling mudah untuk bisa tumbuh kembali pada lahan bekas terbakar, apa lagi jika masih ada jaringan terdahulu yang masih tersisa, maka dengan mudah sisa tanaman akan menumbuhkan pucuk kembali. Tanaman ini juga tidak membutuhkan prasyarat yang khusus dalam pertumbuhannya karena bisa 
berdaptasi pada kondisi kering dan juga terbuka.

\section{Keanekaragaman Jenis}

Untuk menunjukan tingkat keanekaraman jenis pada lahan tidak terbakar dan lahan bekas terbakar maka ditunjukan dengan penelitian kuantitatif yakni dengan menghitung kekayaan jenis menggunakan indeks keragaman jenis $\left(\mathrm{H}^{\prime}\right)$, indeks diversitas Margalef (d) dan nilai Evenness untuk menunjukan Kemerataan jenis (E).

Berikut adalah hasil perhitungan di lokasi terbakar dan Non terbakar:

\begin{tabular}{|l|r|r|r|r|r|r|}
\hline \multirow{2}{*}{\multicolumn{1}{c|}{ Lokasi Penelitian }} & \multicolumn{4}{|c|}{ KHDTK Tumbang Nusa } & \multicolumn{3}{c|}{ TN. Sabangau } \\
\cline { 2 - 7 } & \multicolumn{1}{|c|}{ H' } & \multicolumn{1}{c|}{ d } & \multicolumn{1}{c|}{ H' } & \multicolumn{1}{c|}{ d } \\
\hline Lahan Terbakar & & & & & & \\
Semai & 1,41 & 1,53 & 0,78 & 1,56 & 1,91 & 0,75 \\
Pancang & 1,99 & 2,67 & 0,59 & 2,01 & 3,00 & 0,87 \\
Tiang & 0,66 & 1,89 & 0,25 & 0,91 & 3,12 & 0,65 \\
Pohon & 0,64 & 2,18 & 0,15 & 1,03 & 4,53 & 0,29 \\
\hline Lahan Tidak terbakar & & & & & & \\
Semai & 0 & 0 & 0 & 0,27 & 3,36 & 0,13 \\
Pancang & 1,32 & 1,67 & 0,95 & 0 & 0 & 0 \\
Tiang & 0 & 0 & 0 & - & - & - \\
Pohon & - & - & - & - & - & - \\
\hline
\end{tabular}

Sumber Data: pengolahan data primer

Keragaman jenis yang ditunjukan dengan nilai $\mathrm{H}^{\prime}$ hampir semua menunjukan data tingkat keragamannya masih rendah hingga sedang $1<\mathrm{H}^{\prime}<3$ dan tidak ada yang melimpah, baik pada KHDTK Tumbang Nusa maupun di Sabangau. Untuk nilai kekayaan jenis (Indeks Margalef) angka yang dihasilkan dari penelitian ini juga tidak terlalu menggembirakan dimana karena nilainya di bawah 3,5 hanya pada tingkat pohon di TN. Sabangau yang angkanya mencapai 4,53 yang berarti kekayaan jenisnya termasuk sedang. Penyebaran jenis pada dua lokasi penelitian juga tidak cukup merata, karena masih jauh nilainya dari angka 1, justru pada lahan bekas terbakar untuk tingkat vegetasi pancang di KHDTK justru nilainya mencapai 0,95 . Temuan yang sama ditunjukan dari hasil penelitian Agus, dkk. 2018 dimana keanekaragaman tanaman pada sejumlah tipe lahan gambut tropis di Kalimantan Tengah cenderung memiliki keanekaragaman dari rendah hingga sedang dengan metode analisis indeks shanon, hal ini di karenakan genangan air, $\mathrm{pH}$ 
rendah, kesuburan tanah rendah, toksisitas logam tinggi. Kondisi ini secara garis besar dipengaruhi oleh adanya perubahan penggunaan lahan yang mengakibatkan kadar asam humat tinggi, area aromatik, luas permukaan hidrofobik, dan kemampuan penyimpanan air rendah. Keadaan ini lahan mudah terbakar selama musim kemarau dan rentan terhadap makanan selama musim hujan.

\section{KESIMPULAN DAN SARAN}

\section{Kesimpulan}

Kesimpulan pada penelitian dampak kebakaran hutan pada keanekaragaman hayati di KHDTK Tumbang Nusa dan TN. Sabangau adalah:

1. Dari identifikasi jenis vegetasi, didapatkan hasil bahwa di KHDTK Tumbang Nusa lebih sedikit jenis vegetasi yang ditemui yakni hanya sekitar 20 jenis dan di TN. Sabangau ada sekitar 29 jenis vegetasi. Pada lahan bekas terbakar sangat lambat proses suksesi yang terjadi, permudaan alam dari pengamatan hanya ada sekitar 4 jenis di KHDTK Tumbang Nusa dan 2 jenis di TN. Sabangau. Perbedaan ini dikarenakan kondisi lingkungan yang berbeda, di mana TN.
Sabangau adalah hutan rawa gambut yang hampir selalu basah lantai hutannya, sedangkan di KHDTK Tumbang Nusa adalah lahan gambut yang cenderung lebih tinggi dan agak kering kondisi lantai hutannya.

2. Untuk dominasi jenis ditunjukan dengan nilai INP yang tinggi, semakin besar nilai INP maka komposisi hutan tersebut cukup baik dilihat dari kerapatan dan juga frekwensi kehadiran jenisnya. Di Sabangau nilai dominasi tertinggi adalah Tutup Kabali Diospyros pseudomalabarica pada tingkat pohon, rambutan Hutan Nephelium lappaceum untuk tingkat tiang dan pancang, serta Bangkinang Elaeocarpus glaber $\mathrm{Bl}$ untuk tingkat anakan.

3. Keragaman jenis, kekakyaan jenis dan kemerataan jenis di kedua lokasi penelitian tergolong rendah hingga sedang, tidak ada yang masuk dalam range nilai tinggi.

\section{Saran}

Rekomdenasi dari penelitian ini adalah:

1. Sebaiknya tindakan yang dilakukan adalah dengan meminimalisir terjadinya kebakaran di hutan gambut, dengan upaya meningkatkan 
pengendalian dalam hal ini pencegahan terjadinya kebakaran karena bagaimana pun juga jika sudah terjadi kebakaran akan sulit dikendalikan dan dampaknya lama agar bisa dipulihkan lagi.

2. Melaksanakan rehabilitasi dengan tanaman endemik, terutama tanaman yang mampu bertahan di lahan gambut yang miskin unsur hara dan rawan tergenang dan atau banjir. Terutama di KHDTK Tumbang Nusa dan TN. Sabangau yang memang mebutuhkan perhatian khusus.

\section{DAFTAR PUSTAKA}

Abdul Qiram, M. Dkk. 2019. Studi Biofisik pada Lanskap Hutan Rawa Gambut di Taman Nasional Sebangau: Kasus di Resort Mangkok. Jurnal Ilmu Pertanian Indonesia (JIPI). Vol. 24 (3): 188-200 ISSN 0853-4217 http://journal.ipb.ac.id/index.php/J IPI

Agus C, dkk. 2018. The efect of tropical peat land-use changes on plant diversity and soil properties. International Journal of Environmental Science and Technology https://doi.org/10.1007/s13762019-02579-x

Anonim. 2015. Profil Desa Tumbang Nusa. Pemerintah Desa Tumbang Nusa. Tumbang Nusa.
Bratawinata. A.A. 2001. Ekologi Hutan Hujan Tropis dan Metode Analisis Vegetasi. Departemen Pendidikan Nasional Diktorat Jenderal Pendidikan Tinggi Negeri Indonesia Timur. Samarinda.

Badriyah Siti. 2012. Mengenal Keanekaragaman Hayati.

Penerbit Grasindo.

Irwanto. 2006. Analisis Struktur dan Komposisi Vegetasi untuk Pengelolaan Kawasan Hutan Lindung Pulau Marsegu, Kabupaten Seram Barat, Provinsi Maluku.

Junaedi Eddy. 2016. Mengenal Jenis Hutan Serta Mengungkap Metode Pemadaman Kebakaran Hutan Dan Lahan. Gading Inti Prima.

Marlang Abdullah, M.H. 2015. Buku Hukum Konservasi Sumber Daya Alam Hayati dan Ekosistemnya. Penerbit Mitra Wacana Media.

Purwanto,E. 1998. Isu Lingkungan Seputar Kekeringan dan Kebakaran Hutan. Duta Rimba. Jakarta.

Rahmad, Riandi. 2014. Dampak Negatif Kebakaran Hutan Gambut. Environment Article. https://environmentindonesia.com/dampak-negatifkebakaran-hutan-gambut/

Rachmanandi, Dony dkk. 2017. Keanekaragaman Potensi Regenerasi Vegetasi pada Hutan 
Rawa Gambut: Studi Kasus di Kawasan Hutan Dengan Tujuan Khusus (KHDTK) Tumbang Nusa, Kalimantan Tengah. Jurnal Ilmu Kehutanan edisi II hal: 229238.

https://jurnal.ugm.ac.id/jikfkt

Sucipto Hariyanto dkk. 2008. Teori dan Praktik Ekologi. Airlangga University Press.

Soemarwoto Otto. 2009. Ekologi, Lingkungan Hidup dan Pembangunan. Penerbit Djambatan.

Topografi.https://dishut.kalteng.go.id/page/ 38/topografi diakses 26 Oktober 2019

Tanah. https://tnssebangau.com/tanah di akses 26 Oktober 2019

Yulianti, Rery dkk. (2009). Analisis Hutan Rawa Gambut Pasca Kebakaran di Wilayah Desa Sabangau dan Desa Taruna Jaya. Universitas Gajahmada. Yogyakarta. 